\title{
Factors affecting the technical efficiency of health systems: A case study of Economic Cooperation Organization (ECO) countries (2004-10)
}

\author{
Ramin Ravangard, Nahid Hatam, Abedin Teimourizad, Abdosaleh Jafari
}

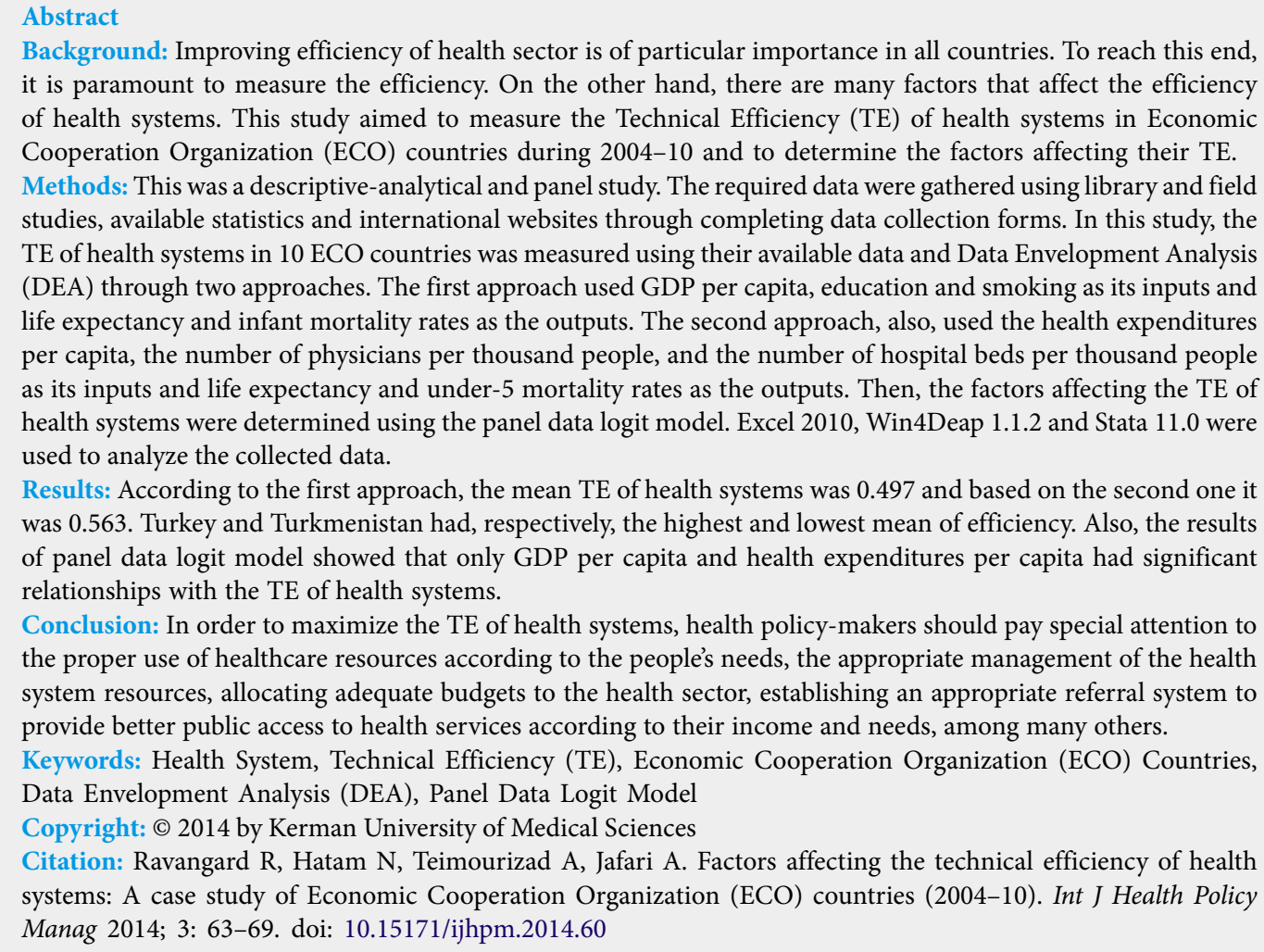
it is paramount to measure the efficiency. On the other hand, there are many factors that affect the efficiency of health systems. This study aimed to measure the Technical Efficiency (TE) of health systems in Economic Cooperation Organization (ECO) countries during 2004-10 and to determine the factors affecting their TE. Methods: This was a descriptive-analytical and panel study. The required data were gathered using library and field studies, available statistics and international websites through completing data collection forms. In this study, the TE of health systems in 10 ECO countries was measured using their available data and Data Envelopment Analysis (DEA) through two approaches. The first approach used GDP per capita, education and smoking as its inputs and life expectancy and infant mortality rates as the outputs. The second approach, also, used the health expenditures per capita, the number of physicians per thousand people, and the number of hospital beds per thousand people as its inputs and life expectancy and under- 5 mortality rates as the outputs. Then, the factors affecting the TE of health systems were determined using the panel data logit model. Excel 2010, Win4Deap 1.1.2 and Stata 11.0 were used to analyze the collected data.

Results: According to the first approach, the mean TE of health systems was 0.497 and based on the second one it was 0.563 . Turkey and Turkmenistan had, respectively, the highest and lowest mean of efficiency. Also, the results of panel data logit model showed that only GDP per capita and health expenditures per capita had significant relationships with the TE of health systems.

Conclusion: In order to maximize the TE of health systems, health policy-makers should pay special attention to the proper use of healthcare resources according to the people's needs, the appropriate management of the health system resources, allocating adequate budgets to the health sector, establishing an appropriate referral system to provide better public access to health services according to their income and needs, among many others.

Keywords: Health System, Technical Efficiency (TE), Economic Cooperation Organization (ECO) Countries, Data Envelopment Analysis (DEA), Panel Data Logit Model

Copyright: (C) 2014 by Kerman University of Medical Sciences

Citation: Ravangard R, Hatam N, Teimourizad A, Jafari A. Factors affecting the technical efficiency of health systems: A case study of Economic Cooperation Organization (ECO) countries (2004-10). Int J Health Policy Manag 2014; 3: 63-69. doi: 10.15171/ijhpm.2014.60

Article History:

Received: 2 May 2014 Accepted: 6 June 2014 ePublished: 8 June 2014

\footnotetext{
*Correspondence to:

Abdosaleh Jafari

Email: abdosaleh.jafari@gmail.com
}

\section{Introduction}

Improving health status and reducing exposure to diseases, maintaining and promoting mental and physical abilities in the personal and social levels are considered as a necessity for improving human welfare (1). Health plays an important role in the growth and economic development of countries through improving labor productivity, reducing the financial burden of diseases, saving healthcare resources (2).

Studies show that more than half of the national resources are being wasted in different countries. In underdeveloped countries, limited resources are used inefficiently and public funds are spent on services that are unsuitable and ineffective (3). Hence it can be said that the proper distribution of health resources and facilities and the efficient use of them are very important, and implementing health system reforms and making precise assessments seem inevitable. These reforms are possible through further examining the policies, increasing efficiency, limiting unnecessary expenses, etc. (4).
In recent decades, health policy-makers have been concerned about their health systems performance and many countries have implemented reforms in their health sector due to their poor performance. However, improving the quality and quantity of health services requires an actual assessment of the performance and efficiency of the health systems. As such, we can ensure the proper balance between resources and outcomes and achievement of the objectives of health systems (5).

One of the most important indicators that can be used to assess the performance of health systems is the proportion of health system outputs to the resources (physical and monetary ones) consumed. In fact, this indicator deals with the issue that how the consequences and outputs resulting from the health sector are in comparison with the existing resources available in the country (6). Efficiency indicates that how good an organization has used its resources in order to produce the best performance over a period of time (7). 
The types of efficiency and a variety of methods to measure it were introduced primarily based on Farrell's method. Farrell proposed that it was more appropriate to compare a firm's performance with the best existing firms in that industry. This method is consistent with the concept of frontier production function that is used as an indicator to measure the efficiency. Frontier production function is defined as the maximum possible amount of product that comes from a certain set of factors of production. Farrell developed his ideas about the efficiency measurement based on the studies conducted by Debreu and Koopmans (8). He defined economic efficiency as the degree of a producer success in minimizing the cost of producing a certain amount of product. He divided economic efficiency into two parts, technical and allocative efficiency. Farrell states that allocative efficiency is the use of the optimal combination of the factors of production. He believes that when the inputs are allocated according to their prices, the profit will be maximized and allocative efficiency is met. On the other hand, a technically efficient unit can create the maximum attainable product using consumption of a certain amount of production factors. In other words, for achieving the maximum TE, the producer should act on the frontier production function (9).

Some health system researchers have studied the TE which the results of some of these studies are as follows:

Pinto in a study of the TE in Italian regional health outcomes using Data Envelopment Analysis (DEA) concluded that the mean of efficiency scores with constant returns to scale was equal to 0.981 and with the variable returns to scale was equal to 0.988 (10). de Cos and Moral-Benito in a study examined the determinants of health system efficiency using DEA in 29 industrialized countries in 2009. The results of the study showed that Australia had the highest efficiency score (0.991) and Hungary had the lowest (0.942) one. Finally, they suggested that policies such as increasing the regulation of prices billed by providers and decreasing the degree of gate keeping could cause gaining more efficiency (11). The results of Haddad et al's study showed that having multiple insurers was related to the low efficiency of the health system. In addition, countries seeking to improve the efficiency of their health systems should pay more attention to the behavior of the people and their welfare (12). The results of Afonso et al's study showed that countries with smaller public sector compared with those with larger public sector had dramatically higher efficiency in their health sector (13). Ramsay estimated the health systems' efficiency in eight countries using 12 indicators related to quality of services, community access to the services and the cost of providing services. The results showed that two indicators of household income and female literacy were the main determinants of health outcomes production (14).

While extensive studies have been conducted on assessing the effectiveness and efficiency of health systems in different countries, including the Organization for Economic Cooperation and Development (OECD) countries and European and the American countries, few studies have been carried out in developing countries most of which have investigated the effects of only one factor on the health system efficiency while many factors have effects on it. Therefore, due to the necessity of paying more attention to improve the productivity and efficiency of the health systems, especially in the countries which are in a group in terms of the economic resources and the structure of their health systems such as Economic Cooperation Organization (ECO) countries that Iran is one of these countries, conducting more studies on the health system efficiency seems necessary.

Therefore, the present study aimed to measure the health systems TE in ECO countries during 2004 to 2010 and to determine the factors affecting their TE using DEA.

\section{Methods}

This was a descriptive-analytical and panel study conducted to measure the ECO countries' TE of health system during 2004 to 2010 using DEA, as well as to determine the factors affecting their health systems TE.

The activity of ECO countries began as the Regional Cooperation Development in July 1964 and its founding members were Turkey, Pakistan and Iran. In 1991, ECO expanded and its number of members reached 10 countries, including Iran, Turkey, Azerbaijan, Pakistan, Afghanistan, Kyrgyzstan, Tajikistan, Kazakhstan, Turkmenistan and Uzbekistan (15).

In the present study, two approaches were used to measure the TE. In the first approach, the inputs which were in the production function of human capital and indirectly involved in the production of health outcomes (inputs beyond the control of health systems) were used. In this approach, the inputs included income, education, smoking, and the outputs were life expectancy and infant mortality rates.

In the second approach, the inputs that were directly involved in the production of health outcomes (inputs under the control of health systems) were used. In this approach, the inputs included health expenditures per capita, number of physicians per thousand people, and the number of hospital beds per thousand people, and the outputs were life expectancy and under-5 mortality rates.

In DEA method, first, the data collected by data collection forms using the library and field studied were entered into Excel 2010. These data were collected using statistics available in international databases such as the databases of the World Health Organization (WHO), the World Bank, the United Nations Development Fund, the ECO countries' National Health Accounts, the Iran statistical Center and Ministry of Health (Department of Health, Policy Council, etc.), and the databases of other international organizations related to 2004 to 2010 . Then, the collected data were transferred to Win4Deap 1.1.2 software (Centre for Efficiency and Productivity Analysis, University of Queensland, Australia) by year and the TE of the ECO countries health systems was calculated.

Finally, the panel data logit model with random effects Maximum Likelihood Method (MLE) was used to estimate the factors affecting the TE of ECO countries health system because the DEA efficiency estimates were binary variables, i.e. they were bounded between 0 and 1 , and the error term had a logistic distribution (16). On the other hand, because the dependent variable was not normally distributed, logit 
model was used instead of the probit model.

The model used in this study was as follows:

If $\mathrm{P}_{\mathrm{i}}$ (the probability of being an inefficient health system) is equivalent to $Y_{i}=0$, then the probability of having an efficient health system is displayed as $Y_{i}=1$. Therefore, the set of variables influencing the probability of having an efficient health system will be as follows: (Equation 1)

$\mathrm{P}_{i}=\mathrm{E}\left(\mathrm{Y}_{\mathrm{i}}=1 \mid \mathrm{X}_{\mathrm{i}}\right)=\frac{1}{1+\mathrm{e}^{-\left(\beta_{1}+\beta_{2} \mathrm{X}_{\mathrm{i}}\right)}}$

So that " $\mathrm{e}$ " is the neper number or the base of natural logarithm. For simplification, the above equation can be rewritten as follows: (Equation 2)

$\mathrm{P}_{\mathrm{i}}=\frac{1}{1+\mathrm{e}^{-\mathrm{Z}_{\mathrm{i}}}}=\mathrm{F}\left(\mathrm{Z}_{\mathrm{i}}\right)$

Where $Z_{i}=\beta_{1}+\beta_{2} X_{i}$. This equation represents the logistic cumulative distribution function (17).

In this study, after calculating the TE scores of ECO countries health systems during 2004 to 2010, the dependent variable was considered as a binary variable in which zero indicated being inefficient and one indicated being efficient.

Considering the independent variables in the first and second approaches, the panel data Logit model with random effects MLE was estimated using Stata 11.0 (Stata Corporation, College Station, Texas). A $P<0.05$ was considered statistically significant.

Results

The results of this study have been presented in two sections. In the first section, the results of measuring TE of ECO countries health systems during 2004-10 based on two mentioned approaches, as well as the comparison of TE among those countries have been shown (Tables 1 and 2). In the second section, the results of estimating the panel data logit model with random effects MLE based on two approaches have been outlined (Tables 3 and 4).

According to the results displayed in Table 1, based on the first approach, only in 2006 and 2007, respectively, two countries $(20 \%)$ and three countries $(30 \%)$ had full TE (TE=1). Also, the results showed that among all ECO countries, only Iran, Turkey and Azerbaijan had full efficient health systems and the TE scores of the health systems in other countries were less than 1 during the studied period. In addition, the mean TE of health systems during this period was 0.497 . Turkey and Turkmenistan had the highest and lowest mean of efficiency,

Table 1. The results of measuring TE of ECO countries health systems based on the first approach (2004-10)

\begin{tabular}{|c|c|c|c|c|c|c|c|c|c|}
\hline Country & 2004 & 2005 & 2006 & 2007 & 2008 & 2009 & 2010 & Mean (2004-10) & Rank \\
\hline Iran & 0.600 & 0.826 & 1.000 & 1.000 & 0.995 & 0.985 & 0.934 & 0.905 & 2 \\
\hline Turkey & 0.765 & 0.957 & 1.000 & 1.000 & 0.998 & 0.991 & 0.989 & 0.957 & 1 \\
\hline Afghanistan & 0.343 & 0.236 & 0.386 & 0.326 & 0.362 & 0.369 & 0.327 & 0.335 & 7 \\
\hline Pakistan & 0.310 & 0.232 & 0.372 & 0.383 & 0.375 & 0.321 & 0.333 & 0.325 & 8 \\
\hline Tajikistan & 0.453 & 0.345 & 0.434 & 0.383 & 0.376 & 0.356 & 0.326 & 0.381 & 6 \\
\hline Uzbekistan & 0.688 & 0.442 & 0.548 & 0.548 & 0.478 & 0.376 & 0.317 & 0.485 & 4 \\
\hline Azerbaijan & 0.542 & 0.712 & 0.705 & 1.000 & 0.788 & 0.868 & 0.767 & 0.538 & 3 \\
\hline Kyrgyzstan & 0.299 & 0.231 & 0.329 & 0.342 & 0.310 & 0.319 & 0.306 & 0.305 & 9 \\
\hline Kazakhstan & 0.308 & 0.489 & 0.510 & 0.536 & 0.449 & 0.498 & 0.527 & 0.473 & 5 \\
\hline Turkmenistan & 0.274 & 0.268 & 0.436 & 0.330 & 0.340 & 0.363 & 0.335 & 0.267 & 10 \\
\hline
\end{tabular}

Table 2. The results of measuring TE of ECO countries health systems based on the second approach (2004-10)

\begin{tabular}{|c|c|c|c|c|c|c|c|c|c|}
\hline Country & 2004 & 2005 & 2006 & 2007 & 2008 & 2009 & 2010 & Mean (2004-10) & Rank \\
\hline Iran & 0.951 & 0.886 & 0.734 & 0.885 & 0.903 & 0.981 & 0.845 & 0.883 & 2 \\
\hline Turkey & 1.000 & 0.986 & 0.846 & 0.953 & 1.000 & 0.996 & 0.962 & 0.963 & 1 \\
\hline Afghanistan & 0.362 & 0.410 & 0.346 & 0.383 & 0.505 & 0.278 & 0.360 & 0.377 & 8 \\
\hline Pakistan & 0.375 & 0.482 & 0.371 & 0.370 & 0.502 & 0.405 & 0.408 & 0.463 & 5 \\
\hline Tajikistan & 0.739 & 0.658 & 0.399 & 0.399 & 0.720 & 0.730 & 0.676 & 0.617 & 4 \\
\hline Uzbekistan & 0.482 & 0.470 & 0.391 & 0.391 & 0.370 & 0.378 & 0.362 & 0.406 & 6 \\
\hline Azerbaijan & 1.000 & 0.867 & 0.773 & 0.789 & 0.921 & 0.761 & 0.887 & 0.856 & 3 \\
\hline Kyrgyzstan & 0.531 & 0.540 & 0.364 & 0.364 & 0.354 & 0.288 & 0.361 & 0.400 & 7 \\
\hline Kazakhstan & 0.375 & 0.358 & 0.278 & 0.278 & 0.289 & 0.325 & 0.481 & 0.340 & 9 \\
\hline Turkmenistan & 0.332 & 0.368 & 0.281 & 0.281 & 0.332 & 0.275 & 0.426 & 0.327 & 10 \\
\hline
\end{tabular}


Table 3. Factors affecting the TE of ECO countries health systems (2004-10) based on the first approach using panel data logit model with random effects

\begin{tabular}{lccc}
\hline Variables & Coefficient & $P>|Z|$ & $\begin{array}{c}\text { Marginal Effect } \\
(\mathbf{d y} / \mathbf{d x})\end{array}$ \\
\hline Smoking & -1.432 & 0.371 & -1.958 \\
Education & 8.149 & 0.105 & 1.024 \\
GDP per capita & 0.007 & 0.003 & 9.366 \\
Constant & -10.151 & 0.001 & - \\
Log likelihood & -11.644 & - & - \\
Number of observations & 70.000 & - & - \\
\hline
\end{tabular}

Table 4. Factors affecting the TE of ECO countries health systems (2004-10) based on the second approach using panel data logit model with random effects

\begin{tabular}{lccc}
\hline Variables & Coefficient & $\boldsymbol{P}\rangle|\mathbf{Z}|$ & $\begin{array}{c}\text { Marginal } \\
\text { Effect (dy/dx) }\end{array}$ \\
\hline $\begin{array}{l}\text { Physician per thousand } \\
\text { people }\end{array}$ & 9.820 & 0.221 & 3.372 \\
$\begin{array}{l}\text { Hospital bed per thousand } \\
\text { people }\end{array}$ & -9.748 & 0.127 & -3.351 \\
$\begin{array}{l}\text { Health expenditures per } \\
\text { capita }\end{array}$ & 0.001 & 0.007 & $<0.001$ \\
$\begin{array}{l}\text { Constant } \\
\text { Log likelihood }\end{array}$ & -0.620 & 0.046 & - \\
\hline Number of observations & -35.937 & - & - \\
\hline
\end{tabular}

respectively. In addition, the results indicated that the mean of health systems TE in ECO countries had fluctuations during 2004-10.

According to the results shown in Table 2, the TE scores of ECO countries health systems during 2004-10 and their comparison among studied countries based on the second approach showed that only in 2004 and 2008, respectively, two countries $(20 \%)$ and one country (10\%) had the full $\mathrm{TE}(\mathrm{TE}=1)$. Also, the results indicated that among all ECO countries, only Turkey and Azerbaijan were fully efficient and the TE scores of other countries health system was less than 1 during the studied period. Furthermore, the mean TE of the health systems during this period was 0.563 . Turkey had the highest mean of efficiency and Turkmenistan had the lowest one. Again, the mean of health systems TE in ECO countries based on the second approach had fluctuations during 2004-10.

The results of the panel data logit model with random effects for ECO countries health systems (2004-10) based on the first approach showed that only GDP per capita had the significant relationship with the health system TE.

Furthermore, education and GDP per capita had positive relationships with the TE of the health systems and smoking had the negative one, so that a one unit increase in GDP per capita and education could increase the probability of being efficient health systems, respectively, 1.024 and 9.366 units. Conversely, a one unit increase in smoking could decrease the probability of being efficient health systems 1.958 units. Also, according to the coefficients of the studied variables, the marginal effect of GDP per capita on the health systems TE was more than that of two other variables (Table 3 ).
In addition, the results of the panel data logit model with random effects for ECO countries health systems (2004-10) based on the second approach showed that only health expenditures per capita had the significant relationship with the health system TE.

Furthermore, health expenditures per capita and the number of physicians per thousand people had positive relationships with the TE of the health systems and the number of hospital bed per thousand people had the negative one, so that a one unit increase in the health expenditures per capita and the number of physicians per thousand people could increase the probability of being efficient health systems, respectively, 3.372 and $<0.001$ units. Conversely, a one unit increase in the number of hospital bed per thousand people could decrease the probability of being efficient health systems 3.351 units. Also, according to the coefficients of the studied variables, the marginal effect of the number of physicians per thousand people on the health systems TE was more that of two other variables (Table 4 ).

\section{Discussion}

The results of the present study showed that the mean of TE during the studied period based on the first approach was 0.497 and based on the second approach was 0.563 . In addition, in both approaches, the highest and lowest means of the TE belonged to Turkey and Turkmenistan, respectively. In addition, in the present study, the mean of health systems TE in ECO countries had fluctuations during 2004-10.

Varabyova and Schreyögg in their study showed that the mean of the TE of the hospital sectors in 31 OECD countries had flactuations during 2000-9 (18). Sabbagh Kermani et al. in their study concluded that the health system TE of 24 Muslim countries had decreased during 2000-5 (19). It should be noted that the studied settings and factors (inputs and outputs) in these studies have somewhat been different. Therefore, the comparison of the results of these studies should be made with cautions.

In the current study, Turkey had the highest mean of TE during 2004-10 based on both studied approaches. The economic statistics and the results of health surveys conducted in Turkey indicated that factors having significant effects on health system performance had one of the highest rates in Turkey among the ECO countries during the studied period. For example, economic statistics and health surveys conducted in Turkey and published by the WHO in 2010 showed that its total expenditures on health per capita at average exchange rate had been 668.4 US dollars and its general government expenditures on health as a percentage of total expenditures on health had been $74.8 \%$ in 2010 (20). On the other hand, Turkmenistan, among the ECO countries, had the lowest mean of TE during 2004-10 based on both studied approaches. This can be due to many factors, including its reduction in labor efficiency because of increased infant and under-5 mortality rates which are the most effective factors on decreasing the human capital (21).

In the present study, according to the results of the first approach, the relationship between GDP per capita and health system TE was positive and significant. The results of 
de Cos and Moral-Benito, Zhang et al. and Ramsay's studies are consistent with the results of the present study $(11,14,22)$. Also, in the current study, the relationship between education and health systems TE was positive but insignificant. This can be due to that high level of education is associated with other determinants of health such as income, job security, working conditions, etc. (23). The results of de Cos and Moral-Benito, and Prasetyo and Zuhdi, Verhoeven et al. and Ramsay's studies $(11,14,24,25)$ confirm the results of the current study. Furthermore, the relationship between smoking and health systems TE in the present study was negative and insignificant. This can be due that smoking, in addition to having negative effects on the individuals' health and reducing their efficiency, can impose heavy costs such as costs related to the treatment of the cancer patients on the healthcare systems $(26,27)$. The results of de Cos and Moral-Benito and Or et al's studies are consistent with the results of the present study $(11,28)$.

In the current study, according to the results of the second approach, the relationship between the number of physicians per thousand people and the health systems TE was positive but insignificant. The results of this study confirm the optimistic scenario of the number of physicians, so that increasing the number of physicians can increase the community's health and this will lead to a reduced needs and demands for healthcare. Therefore, decreasing the health costs because of reduced needs and demands for healthcare can lead to increased efficiency of the health system. The results of Monin et al., Macinko et al., Aakvik and Holmås and Or et al.'s studies (28-31) confirm the present study results. However, the results of the Starfield et al. and Nolte and McKee's studies showed that health outcomes can be improved without any need to increase the physicians-to-population rate $(32,33)$ which are not consistent with the results of the present study. The relationship between hospital beds per thousand people and health systems TE in the present study was also negative but insignificant. The results of Jones and Rowan, Javitt et al. and Kelly's studies confirm the results of the current study (34-36). The results of these studies confirm the pessimistic scenario of the number of hospital beds, so that the increase in the number of hospital beds can increase the amount of patients' unnecessary stay in the hospital which, in turn, causes fewer people requiring hospitalization services can use these services and also increases the pressure of investing in and establishing new healthcare facilities on the health systems. Therefore, if hospital bed occupancy is high, increased length of stay can reduce the hospital productivity and increase the costs and depreciation of hospital resources, and ultimately it will have negative effects on the performance and efficiency of health systems (37).

In addition, the relationship between health expenditures per capita and health systems TE in the current study was positive and significant, so that rising health expenditures can lead to the health improvement through increasing access to health services. Also, it can be said that higher efficiency and health production can be achieved through larger government investments in more cost-effective interventions $(32,37)$. The results of Varabyova and Schreyögg, Grigoli, Jafarov and Gunnarsson, Ramsay and Evans et al.s studies are consistent with the results of the current study $(14,18,38-40)$.

\section{Limitations}

This study had a number of limitations. Using DEA method to measure the efficiency has some limitations. DEA is deterministic and its findings depend on the countries and variables in the dataset. Also, it measures only relative efficiency. Therefore, any change in the type and number of countries and variables included in the dataset can result in the different findings. On the other hand, the factors and variables studied in this research were selected based on the accepted models of population health, as well as the data availability because DEA requires a complete dataset.

\section{Conclusion}

Overall, the results of this study showed that, in the ECO countries, health expenditures per capita and GDP per capita had significant effects on the health systems TE. In addition, GDP per capita, education, the number of physicians per thousand people and the health expenditures per capita had positive relationships, and smoking and hospital beds per thousand people had negative relationships with the health systems TE. Finally, the effects of GDP per capita and the number of physicians per thousand people on the health systems TE were more than other variables.

Therefore, in order to maximize the efficiency of health systems of the studied countries, it is suggested that policymakers and health managers in these countries should pay special attention to the factors such as the promotion of public education level, the appropriate use of healthcare providers according to the needs of the population, proper management of the health systems resources especially physicians, allocating adequate budgets to the health sector, establishing suitable referral system to provide better access to health services for people according to their income and healthcare needs, etc. Finally, it is recommended to conduct similar methodology in future studies to determine other factors (under and beyond the control of health systems) affecting the efficiency of health systems.

\section{Acknowledgements}

The present article was extracted from the thesis written by Abedin Teimourizad and was financially supported by Shiraz University of Medical Sciences grants No. 92-6595. The authors would like to thank Dr. Nasrin Shokrpour at the Center for Development of Clinical Research of Nemazee Teaching Hospital for her editorial assistance.

\section{Ethical issues}

The Ethics Committee of Shiraz University of Medical Sciences approved the study (Project No: 92-6595).

\section{Competing interests}

The authors declare that they have no competing interests.

Authors' contributions

$\mathrm{RR}$ and AJ contributed to conceiving and designing the study. The data was collected by AT; and was analyzed and interpreted jointly by RR, AJ, NH, and AT. All authors contributed equally in writing the manuscript. All authors reviewed 
and approved the final manuscript.

Authors' affiliations

Department of Health Services Administration, School of Management and Information Sciences, Shiraz University of Medical Sciences, Shiraz, Iran.

\section{References}

1. Bankauskaite V, Dargent G. Health systems performance indicators: methodological issues. Presupuesto y Gasto Público 2007; 49: 125-37.

2. Clayton AC. Assessing the Productive Efficiency of US Health Care: Comparison of Analytical Methods [internet]. Honors Projects 2010: 106. Available from: http://digitalcommons.iwu. edu/econ_honproj/106/

3. Collins C, Green A. Decentralization and primary health care: some negative implications in developing countries. Int $\mathrm{J}$ Health Serv 1994; 24: 459-76. doi: 10.2190/g1xj-px06-1lvd-2fxq

4. Schieber GJ. Preconditions for health reform: experiences from the OECD countries. Health Policy 1995; 32: 279-93. doi: 10.1016/0168-8510(95)00740-J

5. Varela PS, de Andrade Martins G, Fávero LPL. Production efficiency and financing of public health: an analysis of small municipalities in the state of São Paulo--Brazil. Health Care Manag Sci 2010; 13: 112-23. doi: 10.1007/s10729-009-9114-y

6. World Health Organization (WHO). The world health report 2000 - health systems: improving performance. Geneva: WHO; 2000.

7. Vitaliano DF, Toren M. Hospital cost and efficiency in a regime of stringent regulation. East Econ J 1996: 22; 161-75.

8. Mehregan MR. Quantitative models for assessment of organizations performance (DEA). Tehran: School of Management, Tehran University; 2008.

9. Torkamani J. The impact of insurance on farmers' TE and risk aversion: the use of stochastic frontier production functions. Journal of Agricultural and Development Economics 2009; 22 : 45-8.

10. Pinto C. TE in the Production of Aggregate Regional Health Outcomes in Italy. Finance Research 2013; 2: 4-11.

11. de Cos PH, Moral-Benito E. Determinants of health-system efficiency: evidence from OECD countries. Int $J$ Health Care Finance Econ 2014: 14; 69-93. doi: 10.1007/s10754-013-9140-7

12. Hadad S, Hadad $Y$, Simon-Tuval T. Determinants of healthcare system's efficiency in OECD countries. Eur J Health Econ 2013; 14: 253-65. doi: 10.1007/s10198-011-0366-3

13. Afonso A, Schuknecht L, Tanzi V. Public sector efficiency: an international comparison. Public Choice 2005; 123: 321-47. doi: 10.1007/s11127-005-7165-2

14. Ramsay CR, Grant A, Wallace S, Garthwaite P, Monk A, Russell I. Statistical assessment of the learning curves of health technologies. Health Technol Assess 2001; 5: 1-79.

15. Wooldridge J. Econometric Analysis of Cross Section and Panel Data. Cambridge: MIT Press; 2002.

16. Jones AM. Applied econometrics for health economists: a practical guide. 2nd edition. Oxford: Radcliffe Publishing; 2007.

17. Gujarati DN. Basic Econometrics. 4th edition. New York: McGraw-Hill; 2003.

18. Varabyova Y, Schreyögg J. International comparisons of the TE of the hospital sector: Panel data analysis of OECD countries using parametric and non-parametric approaches. Health Policy 2013; 112: 70-9. doi: 10.1016/j.healthpol.2013.03.003

19. Sabbagh Kermani M, Yavari K, Basakha M, Shahtahmasbi E. Education and Health Expenditure Efficiency in OIC Countries: Using a DEAApproach. The Economic Research 2009; 9: 65-87.

20. World Health Organization (WHO). WHO European Region: Turkey statistics summary (2002 - present) [internet]. [cited 2014 February 5]. Available from: http://apps.who.int/gho/data/node.
country.country-TUR

21. World Health Organization (WHO). WHO European Region: Turkmenistan statistics summary (2002 - present). [cited 2014 February 5]. Available from: http://apps.who.int/gho/data/node. country.country-TKM

22. Zhang N, Hu A, Zheng J. Using Data Envelopment Analysis approach to estimate the health production efficiencies in China. Frontiers of Economics in China 2007; 2: 1-23. doi: 10.1007/ s11459-007-0001-5

23. Gustavson KR, Lonergan SC, Ruitenbeek HJ. Selection and modeling of sustainable development indicators: a case study of the Fraser River Basin, British Columbia. Ecol Econ 1999; 28: 117-32. doi: 10.1016/s0921-8009(98)00032-9

24. Verhoeven M, Gunnarsson V, Carcillo S. Education and Health in G7 Countries: Achieving Better Outcomes with Less Spending. Washington, DC: International Monetary Fund; 2007. doi: $10.5089 / 9781451868265.001$

25. Prasetyo AD, Zuhdi U. The Government Expenditure Efficiency towards the Human Development. Procedia Economics and Finance 2013; 5: 615-22. doi: 10.1016/s2212-5671(13)00072-5

26. Sumaili FK, Milimo J. Health Sector Reform Review: A Report. Lusaka: Participatory Assessment Group (PAG); 1996.

27. Retzlaff-Roberts D, Chang CF, Rubin RM. TE in the use of health care resources: a comparison of OECD countries. Health Policy 2004; 69: 55-72. doi: 10.1016/j.healthpol.2003.12.002

28. Or Z, Wang J, Jamison D. International differences in the impact of doctors on health: a multilevel analysis of OECD countries. J Health Econ 2005; 24: 531-60. doi: 10.1016/j. jhealeco.2004.09.003

29. Aakvik A, Holmås TH. Access to primary health care and health outcomes: the relationships between GP characteristics and mortality rates. J Health Econ 2006; 25: 1139-53. doi: 10.1016/j. jhealeco.2006.04.001

30. Macinko J, Marinho de Souza Mde F, Guanais FC, da Silva Simões CC. Going to scale with community-based primary care: an analysis of the family health program and infant mortality in Brazil, 1999-2004. Soc Sci Med 2007; 65: 2070-80. doi: 10.1016/j.socscimed.2007.06.028

31. Monin JL, Lancellotti P, Monchi M, Lim P, Weiss E, Piérard $\mathrm{L}$, et al. Risk score for predicting outcome in patients with asymptomatic aortic stenosis. Circulation 2009; 120: 69-75. doi: 10.1161/circulationaha.108.808857

32. Starfield B, Shi L, Macinko J. Contribution of primary care to health systems and health. Milbank Q 2005; 83: 457-502. doi: 10.1111/j.1468-0009.2005.00409.x

33. Nolte E, McKee CM. Measuring the health of nations: updating an earlier analysis. Health Aff (Millwood) 2008; 27: 58-71. doi: 10.1377/hlthaff.27.1.58

34. Jones J, Rowan K. Is there a relationship between the volume of work carried out in intensive care and its outcome? Int J Technol Assess Health Care 1995; 11: 762-9. doi: 10.1017/ s0266462300009193

35. Javitt JC, Street DA, Tielsch JM, Wang Q, Kolb MM, Schein $\mathrm{O}$, et al. National Outcomes of Cataract Extraction: Retinal Detachment and Endophthalmids after Outpatient Cataract Surgery. Ophthalmology 1994; 101: 100-6. doi: 10.1016/S01616420(13)31251-2

36. Kelly JV. What do mortality studies reveal about hospital volume, teaching status, and ownership? Int J Technol Assess Health Care 1990; 6: 239-52. doi: 10.1017/s0266462300000763

37. Borghans I, Heijink R, Kool T, Lagoe RJ, Westert GP. Benchmarking and reducing length of stay in Dutch hospitals. BMC Health Serv Res 2008; 8: 220. doi: 10.1186/1472-69638-220

38. Grigoli F. Public Expenditure in the Slovak Republic: Composition and TE. Washington, DC: International Monetary Fund; 2012. 
doi: 10.5089/9781475505214.001

39. Jafarov E, Gunnarsson V. Government spending on health care and education in Croatia: efficiency and reform options. Washington, DC: International Monetary Fund; 2008. doi: 10.5089/9781451869958.001
40. Evans RG, Lomas J, Barer ML, Labelle RJ, Fooks C, Stoddart $\mathrm{GL}$, et al. Controlling health expenditures--the Canadian reality. N Engl J Med 1989; 320: 571-7. Doi: 10.1056/ nejm198903023200906

\section{Key Messages}

Implications for policy makers

According to the results of the present study, in order to achieve the maximum efficiency of the health systems of Economic Cooperation Organization (ECO) countries, policy-makers and healthcare managers can benefit from the following strategies:

- Proper management of health resources, including beds, physicians, and so on, in order to reduce the healthcare costs and increase access to health services.

- Educate and inform the managers and people about the healthcare resources and how to use them properly.

- Monitoring and evaluating the health system for identifying inefficient units and departments and taking measures to improve their performance.
Implications for public

Since members of Economic Cooperation Organization (ECO) are developing countries with limited resources, awareness of the risk factors decreasing the health system technical efficiency, including smoking and inefficient use of healthcare resources and facilities, and attempts to reduce them can increase their population access to health services and also avoid the waste of available resources. In fact, these factors have significant effects on the economic development of these countries. Furthermore, inequalities in health and people's exposure to catastrophic health expenditures can be reduced through the appropriate allocation of adequate funds and budgets to the health sectors. 